\title{
Dam Data Collection and Monitoring System
}

\author{
Nikhil M. Dhandre ${ }^{1}$, M. M. Jadhav ${ }^{2}$ \\ ${ }^{1}$ Sinhgad College of Engineering, Pune, India \\ ${ }^{2}$ Professor, Sinhgad College of Engineering, Pune, India
}

\begin{abstract}
In India, most of the smaller Dams are manually monitored and sending data with normal modes. Dam parameters' data collection is mostly unavailable in these systems. Dam researchers want dam parameters data for their research. Common people also unaware about dam parameters mainly dam water level and gate status. To solve these problems we are proposing system which includes GUI software at dam site. It is running on controller and capable of dumping manual observations taken by dam parameter observer into data logger. For monitoring purpose web-portal is designed which will display reading obtained by dam parameters' observer. For remote authorities facility of Email is also included as threshold level is crossed by water level. This proposed system is based on Internet so that data sharing can be possible using web database.
\end{abstract}

Keywords: Dam parameters, GUI, Internet, monitoring system, web-portal.

\section{Introduction}

In our regular life dam and weather conditions play an important role. These are resultant factors that cannot be ignored. As we aware that our national economy is growing faster and agricultural factor is prime source of it due to lots of employments is provided by this only. For agricultural irrigation dams are very important as they store water and keep it for long time.

At present authorities undertaking dams are facing problems in collection of dam data and monitoring the parameters.

Many dam researchers need to apply dam parameters into their research and also modify them. As central database for dam is not available thus they face problems in well storage of data.

Normal people like farmers and others are unaware of these general parameters like water level, gate opening, amount of rainfall, temperature, humidity; so they face problems sometimes.

Due to heavy rainfall, there is a sudden increase in water level then Dam authorities have to open gate. In such condition normal people are unaware and they face sudden disasters like flood.

When dam back water increases above a certain level (i.e. dam danger water level) it may cause damage to firms of farmers as well as other things.

The conception abaft by this system is to develop a webportal which will help in monitoring dam parameters like water level, rainfall, gate position, temperature, humidity etc.

\section{Proposed Methodology}

Figure: 1 shows the system architecture of the dam data collection and monitoring system. Architecture is divided into four parts:
A. GUI Software
B. Controller
C. Connectivity
D. Output

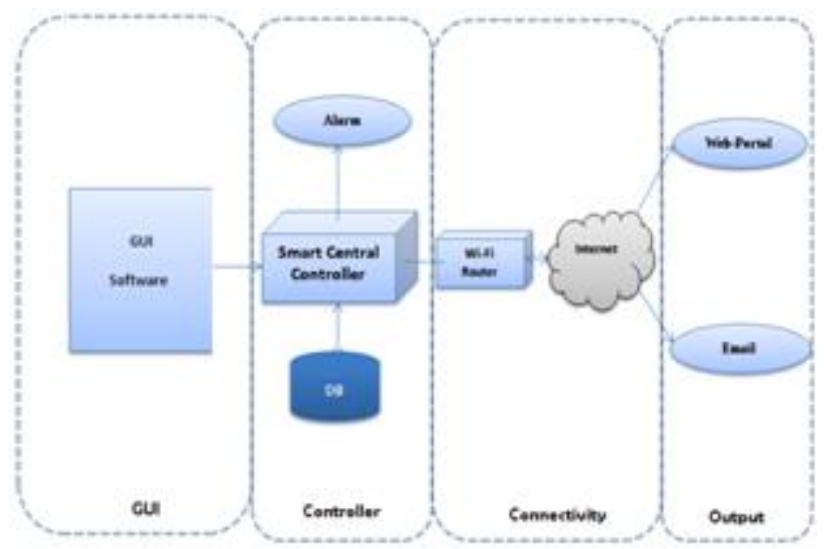

Figure 1: System Architecture of Dam data collection and monitoring system

The hardware and software used in Experimental setup of this system are listed as below:

1) Hardware Used:

- Raspberry pi 3

2) Software Used:

- Raspbian Jessie OS

- MySQL DB

- Apache2

- Python 2

- PHP and html

- Java Script

- Libra office

\section{A. GUI Software}

Most of dams have the preinstall sensor on dam site. Some of those are analog and other digital. With the help of this observed data entered at the dam observer site.GUI software for dam data collection and monitoring system is developed using python for multi-platform compatibility. In this 


\section{International Journal of Science and Research (IJSR) \\ ISSN (Online): 2319-7064}

Index Copernicus Value (2013): 6.14 | Impact Factor (2015): 6.391

software data sending facility directly through Email is also possible.

\section{B. Controller}

System is based on Internet communication so controller plays important role. It is heart of this system. Smart controller plays vital role here. It acts as small computer for running GUI software for manual data entry. Data logger is used for storing all fetch data from sensor. In data logger systematic storing of data can be possible as it is based on MySQL. The response time can be reduced using database in system for query firing though web-portal. Smart controller is used as server for hosting web-portal.

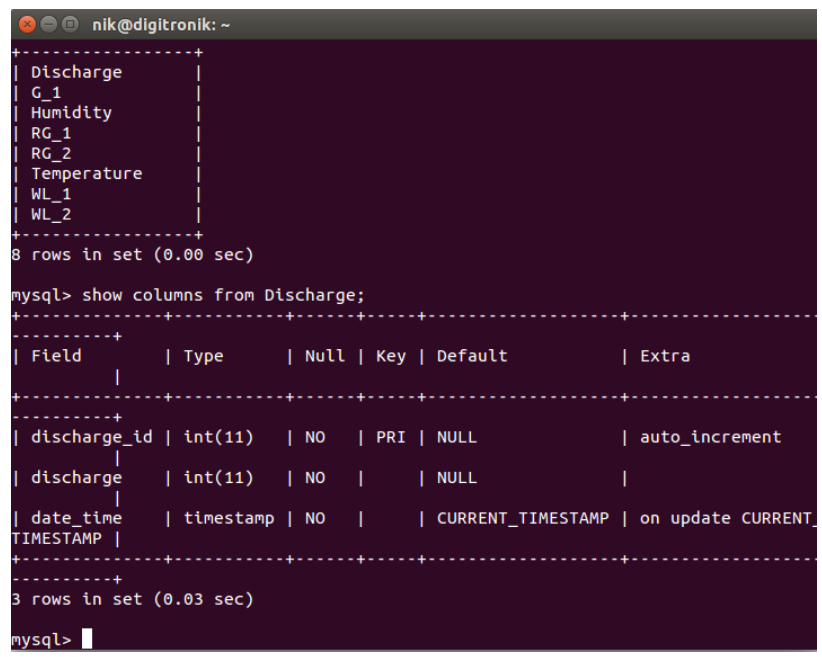

Figure 2: Database Structure

Operation system is mainly based on smart controller which performs operation on data from database and takes decisions like alert on basis of water level.

The smart controller is very useful because of the following advantages:

- Linux platform compatibility

- Data logger for database management.

- Server for web hosting

- Responsible for control system keeps a dynamical balance through self-configure as well as self-organize.

- Low power consumption.

- Small in size.

- Low cost.

\section{Connectivity}

Controller is capable of running Internet on it, so here Internet act as communication link for hosting web-portal. Monitoring is possible due to web hosting with means of computers and mobiles. As it is based on IoT technology so that the database sharing also possible to other system.

\section{Output}

In output system monitoring tools are there like Computer, Mobile and Tablet for monitoring dam parameters with webportal. Email facility also used for monitoring and alert purpose.

\section{Flow Diagram}

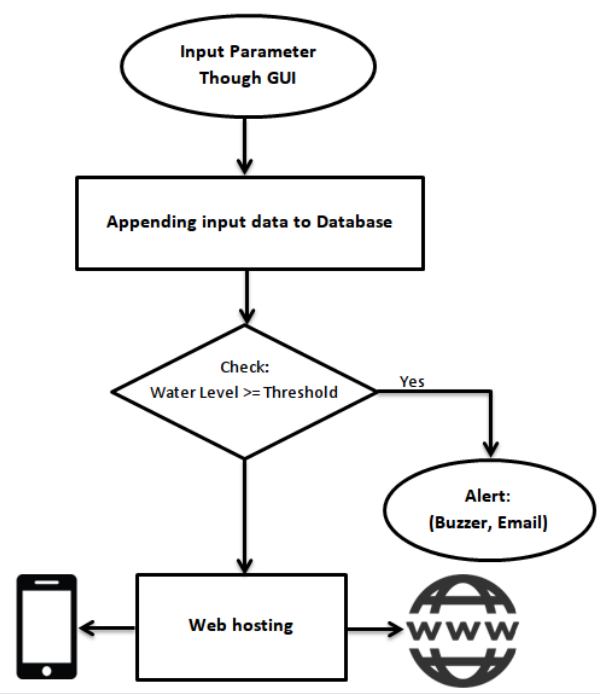

Figure 3: flow diagram of dam data collection and monitoring system

- Observed dam parameters taken from GUI software.

- Controller dumps those parameters data into the MySQL database with separate tables.

- Check for water level if water level cross threshold value (10 FT in experimental setup) sends alert email and buzzer warning.

- With help of Apache 2 web hosting done by controller with fetching data form database.

\section{Algorithm}

The algorithm for this system is as follows:

- Providing observed dam parameter to GUI Software

- Dump the data in database

- Perform operation on data using controller

- Host web-portal with controller

- Generate Alert with respect to threshold values of water level

\section{Result and Discussions}

\section{A. GUI Software}

Figure 3 shows GUI software for dam data collection and monitoring system develop in python. As python is open source and multiplatform language is compatible with most of platforms presently available.

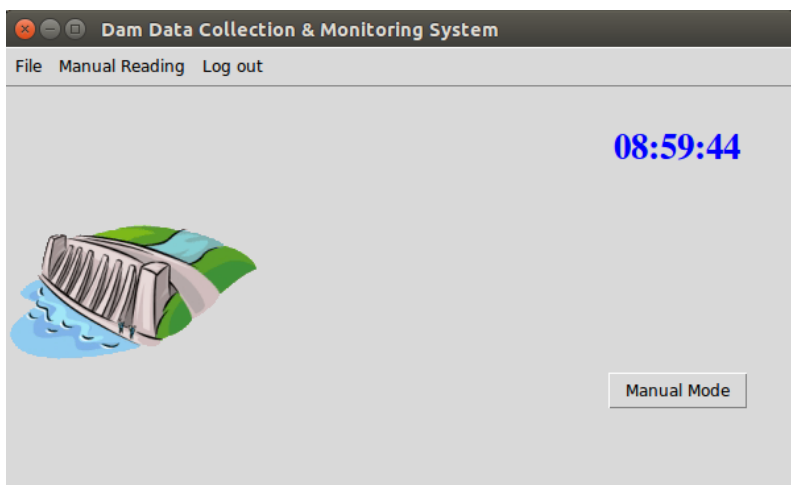

Figure 4: GUI Software: Main window 


\section{International Journal of Science and Research (IJSR) \\ ISSN (Online): 2319-7064}

Index Copernicus Value (2013): 6.14 | Impact Factor (2015): 6.391

Figure shows manual reading window of GUI Software. With this window data logging can be done in database. Python script firing query on database at back end of GUI.

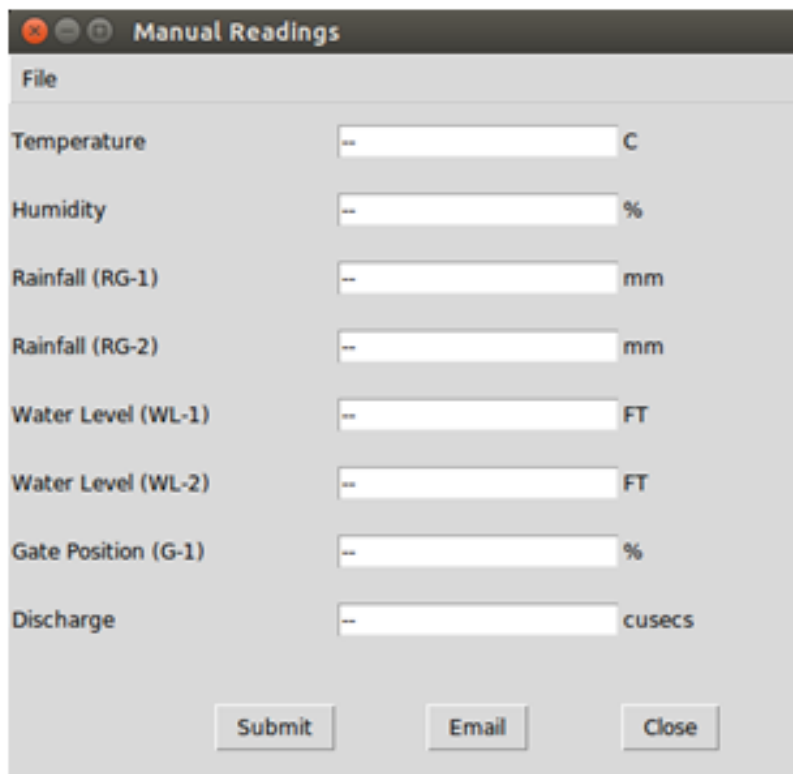

Figure 5: GUI Software: Manual Reading’s window

\section{B. Web-Portal}

Web-portal as shown in Figure:6.It is used for monitoring the real time dam parameters for Dam authority, Dam researchers and Normal people also.
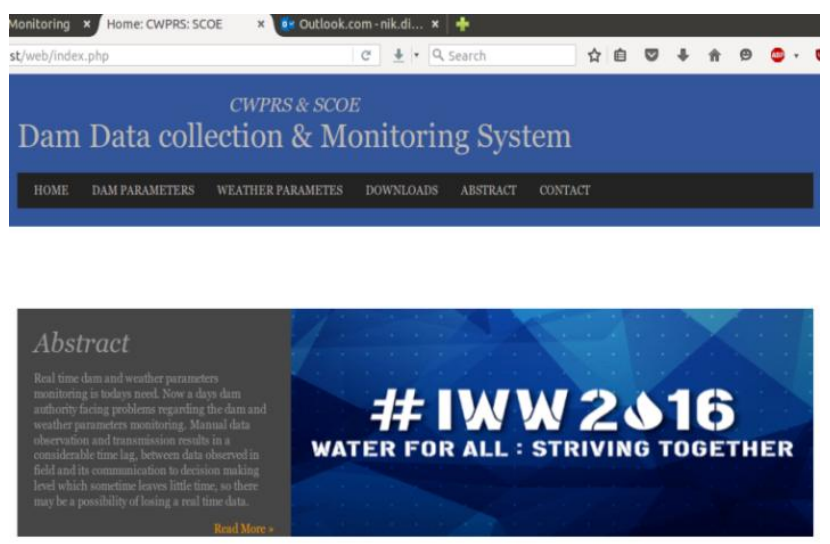

Figure 6: Web-Portal: DPMS: Home

Figure: 7 shows the real time dam parameters on web-portal. It shows the current water level of Dam (WL-1), back water level of Dam River (WL-2), gate position, and discharge from gate.

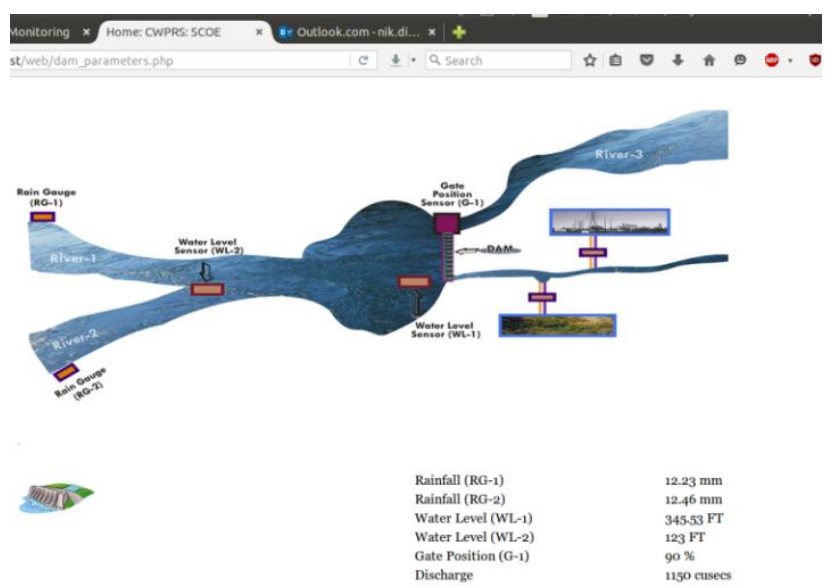

Figure 7: Web-Portal: Dam Parameters

Figure: 8 show real time weather parameters hosted on webportal are Water level, Temperature and Humidity.

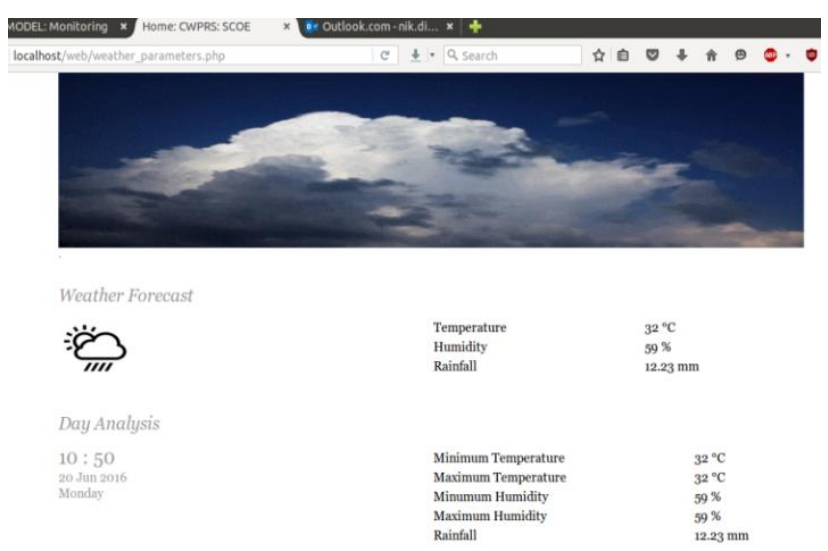

Figure 8: Web-Portal: Weather Parameters

Figure: 8 download windows. For Dam researchers requires the Dam parameters in CSV format for their research.

Though this direct query can fire on database and download it easily.
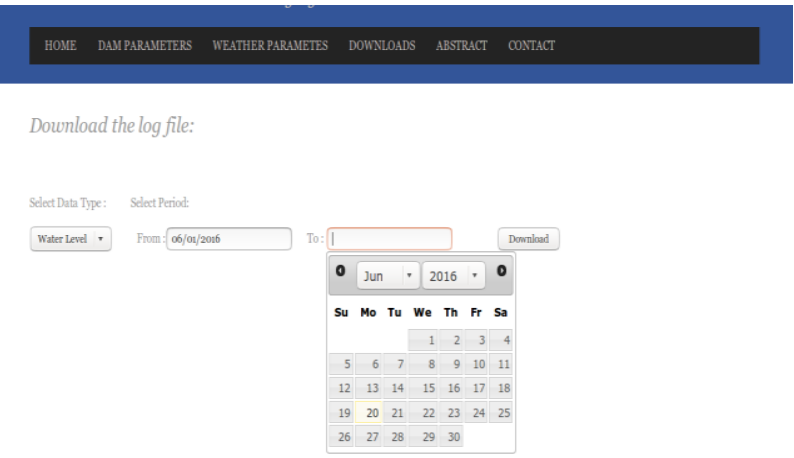

Figure 9: Web-Portal: Download Parameters

\section{Alert}

Figure: 10 show the alert Email of all parameter and report time. When water level increase above threshold value alert Email is send by controller to dam authority and other subscriber. In this threshold level is set at 345 FT.

Volume 5 Issue 6, June 2016 www.ijsr.net 


\section{† New Reply $/ \checkmark$ Delete Archive Junk $/ \checkmark$ Sweep Move to $\checkmark$ Categories $\checkmark$}

DAM Parameters Report

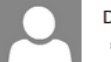

Dam and Weather Parameter Monitoring System

Report time : 2016-06-20 10:48:56

Temperature $=32.0 \mathrm{C}$

Humidity $=59.0 \%$

Rainfall(RG-1) $=12.23 \mathrm{~mm}$

Rainfall( $(\mathrm{RG}-2)=12.46 \mathrm{~mm}$

Water Level $(\mathrm{WL}-1)=345.53 \mathrm{FT}$

Water Level $(\mathrm{WL}-2)=123.0 \mathrm{FT}$

Gate Positon $=90 \%$

Discharge $=1150$ cusec

Figure 10: Alert: Email

\section{Conclusion and Future Scope of Work}

It will help for easy monitoring of dam parameter to Dam authority, Dam researchers, Normal People by using Web portal. It will provide data collection system so that previous data will be useful to Dam authority as well as Dam researchers. It will provide Email and Alarm alert facility for remote authority as water level crosses threshold value. In future, autopilot mode can also be possible with the same system so that manual data entry can be replaced by an automatic sensor system and dam automation is also possible like automatic gate opening system.

\section{References}

[1]D. A. Bagade, "Real time decision support system: Maharashtra." Unpublished.

[2] D. Pandit, G. Jorgensen, A. Klinting, and F. Hansen, "Real time stream flow forecasting and reservoir operation system for krishna and bhima river basins in maharashtra (rtsf and ros)," Hydrology Project II 63800247, Government of Maharashtra Water Resources Department, 2013.

[3] B. Kang, S. Park, T. Lee, and S. Park, "Iot-based monitoring system using tri-level context making model for smart home services," in Consumer Electronics (ICCE), 2015 IEEE International Conference on, pp. 198 -199 , Jan 2015.

[4] M. Wang, G. Zhang, C. Zhang, J. Zhang, and C. Li, "An iot-based appliance control system for smart homes, " in Intelligent Control and Information Processing (ICICIP), 2013 Fourth International Conference on, pp. 744-747, June 2013. 